\title{
Emergency medicine in Oman: current status and future challenges
}

\author{
Nasser Hammad Al-Azri
}

Received: 27 August 2009 / Accepted: 21 November 2009/Published online: 11 December 2009

(C) Springer-Verlag London Ltd 2009

\begin{abstract}
The Sultanate of Oman has a relatively young national health care system that could demonstrate its high performance at an international level. Emergency medicine as a specialty has developed rapidly in the country over the last decade. This has involved the parallel development of local emergency residency training, prehospital emergency care, and emergency nursing programs. This article reviews the progress of emergency care practice in this country from a general primary care system toward becoming an established specialty in hospital, prehospital, and private emergency care settings. It also describes aspects of undergraduate, postgraduate, and continuous emergency medicine education in the country. Further, a glimpse into academic emergency medicine and emergency nursing is provided. Since it describes a developing specialty, the article also attempts to address briefly major future challenges and their importance to the future development of the specialty in Oman.
\end{abstract}

Keywords Oman · Emergency care $\cdot$ Prehospital care

"Medicine in Oman is not easy. I suppose the difficulties are no different from those facing the average general practitioner in Britain... But the sun illuminates all the obstacles in management with brilliant clarity" [1].

The views expressed in this paper are those of the author and not those of the editors, editorial board or publisher.

N. H. Al-Azri $(\bowtie)$

Medical Department, Petroleum Development Oman, P.O. Box 134, Akhdar PC 516 Dhahira, Oman

e-mail: dralazri@yahoo.com

\section{Introduction}

The Sultanate of Oman is located in the southeastern corner of the Arabian Peninsula with a land area of approximately $309,500 \mathrm{~km}^{2}$, predominantly comprising desert (Fig. 1). The coastline stretches for $\sim 1,700 \mathrm{~km}$. This coastline borders three seas: the Arabian Gulf, the Gulf of Oman, and the Arabian Sea. This fact, in addition to control over the Strait of Hormuz, has given this country a special geopolitical and economic importance throughout history. The country is divided into four governorates and five regions for administrative purposes.

According to the latest national census in 2003, the total population is estimated to be $2,340,815$ [2]. Over one third of the population is aged less than 15 years. Urbanized population accounts for more than $75 \%$ of the total country population. The economic surge in Oman is closely tied to the discovery of oil and the beginning of its export at the end of the 1960s. In July 1970, Sultan Qaboos bin Said became the ruler of Oman and formed a new government that initiated comprehensive development plans in all sectors. Along with the economic and political changes that followed, social and cultural transformations began to occur in the country.

\section{Health care in Oman}

Prior to 1970 , Oman had no national health care system. A few missionary hospitals existed in the capital, Muscat. These, along with the British Embassy Hospital, were the only providers of public biomedical health care. Providing free health care to all citizens was one of the key objectives of the new government established in 1970. Considering these facts, it is a significant achievement for the country to rank first in the world with regard to performance on a 
health level and eighth in overall performance, according to WHO Health System Attainment and Performance Estimates [3]. Major government investments in modernizing the health care sector over 30 years have proved successful in utilizing available economic resources efficiently.

The health care system in Oman is population based and provided mainly through Ministry of Health $(\mathrm{MoH})$ institutions. Public health institutions are provided throughout the country in a tiered structure. Primary and extended health care centers are extensively distributed in order to cater to the widely dispersed villages and local communities even in rural areas. Secondary care hospitals are located in large towns, called Wilayat. Tertiary care hospitals are mainly located in Muscat. In 2008, there had been more than 3 million outpatient visits to government hospitals, and more than 8 million outpatient visits to primary health centers and extended health centers in the country. In addition to the $\mathrm{MoH}$ institutions, many other governmental bodies and organizations provide medical services for their employees and dependents.

\section{Emergency care in Oman}

\section{Hospital-based emergency care}

At present, all tertiary and secondary hospitals in the country have emergency departments (EDs) as part of their

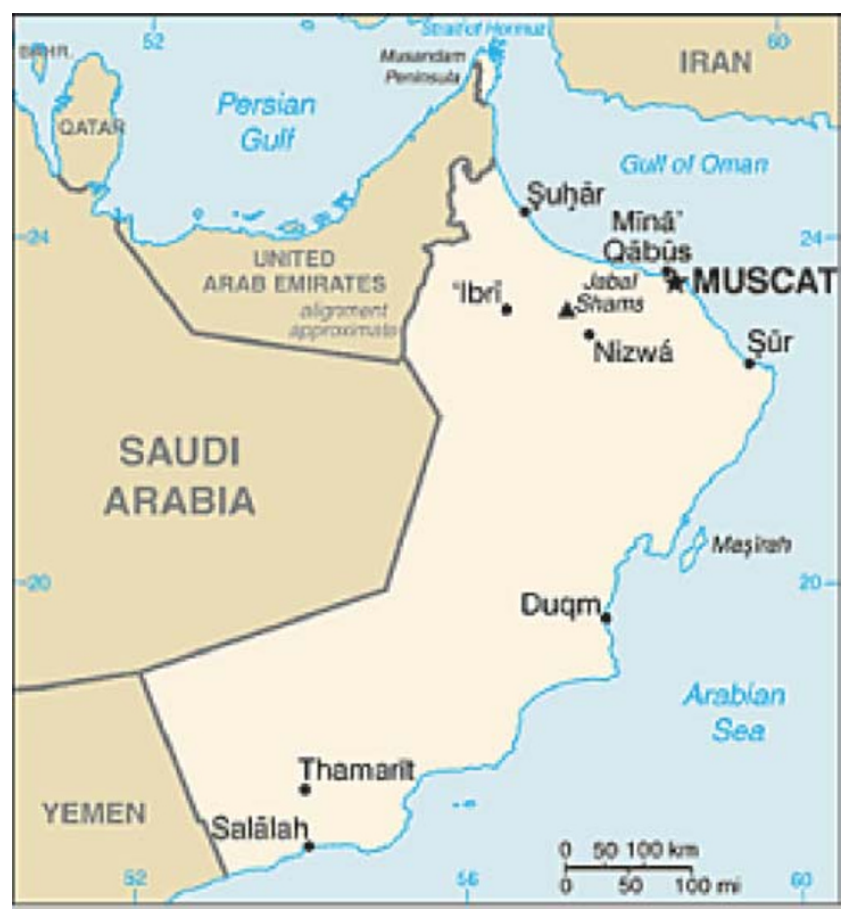

Fig. 1 Map of Oman (reproduced from the CIA World Factbook. Available via: https://www.cia.gov/library/publications/the-worldfactbook/geos/mu.html) infrastructure. However, these departments are mostly staffed by general medical officers although graduates from local and foreign residency programs have begun to hold positions in these departments in tertiary hospitals as well as in some secondary ones. Most of these departments are well equipped to deal with diverse emergency cases. Because of the mountainous nature of the land, primary care centers are distributed extensively throughout the country. These include health centers, extended health centers, and local hospitals. These serve as the primary contact points for emergencies, particularly in rural areas. Although some of them are prepared for emergencies, others lack basic equipment and trained staff to carry out even primary emergency care. The development of these centers, which are an important link in the health care system, is a real challenge for improving the chain of survival in the country.

\section{Prehospital emergency care}

National prehospital medical services did not exist in the country until recently. In 2004, the Royal Oman Police (ROP), in collaboration with the $\mathrm{MoH}$, officially launched the National Ambulance Service, called "Isa' af." The Isa' af service started its operations initially within the capital area but gradually expanding to cover the entire country. Ambulance staff have to undergo local training and qualify as advanced emergency medical technicians. The ambulance unit has a fleet of modern well-equipped ambulances linked through an advanced telecommunications system to the ROP's telecommunication center in order to ensure smooth, coordinated, and timely operations. The service aims to have a response time of less than $10 \mathrm{~min}$ in $80 \%$ of cases attended to in urban areas and $20 \mathrm{~min}$ in rural areas [4].

\section{Private emergency care}

The evolving private health sector is a promising provider of emergency medical services. Many of the recently established private hospitals have EDs with ambulance services available. One private emergency system worth mentioning here is that of Petroleum Development Oman (PDO), the largest oil corporation in the country-its areas of operation cover nearly one third of the country and the combined staff and contractor workforce exceeds 40,000 employees, distributed mostly in sparsely populated areas. Over its more than 40 years of operations, PDO has developed a system of medical emergency response (MER) that ensures availability of medical help for employees as well as local residents within its concession area within a reasonable time. The medical system involves central clinics supervising satellite clinics distributed throughout 
the desert. Central clinics provide remote medical support and logistics as required during medical emergencies. The medical team provides a combination of field-based as well as clinic-based care to patients, in what might be termed "primary emergency care." PDO relies on a tiered structure of employees, first aiders, and medical teams in order to ensure a timely and practical approach to emergencies. This system could be considered the oldest prehospital emergency system in the country.

\section{The birth of emergency medicine (EM) as a specialty}

EM as a specialty

The "Accident \& Emergency" Department has been a part of most hospitals in the country since their establishment. Nevertheless, EM was not at first recognized as an independent specialty. General medical officers would manage these sections with backup and support from other departments in the hospital. With the establishment of tertiary care hospitals, and along with the established medical school at Sultan Qaboos University, the need for specialized EDs was soon realized. Sultan Qaboos University Hospital, being the premier medical teaching institution in the country, was one of the first to establish an ED with medical staff recognition as an independent department. Shortly thereafter, other tertiary, and recently some secondary care hospitals, started to have EDs as an independent specialty.

In the process of evolution of a medical specialty, challenges and obstacles are almost inevitable. In Oman, not the least of these was the struggle for a formal recognition of EM by medical authorities as an independent specialty. EM had to be defined in terms of needs and necessities for the local community within the already existing medical system. Another challenge, which still exists, is the acceptance of EM among other specialties as an independent specialty with defined roles and responsibilities and not only an intermediate system for patient care. Further vertical and horizontal development of the specialty in Oman is closely related to issues of availability of qualified staff, costs, and access to care.

EM in undergraduate medical education

With the gradually evolving system of specialization, especially in tertiary hospitals, EM could also gain a foothold in the undergraduate medical education curriculum to become one of the mandatory rotations for clinical students. The rotation currently includes clinical exposure to emergency practice as well as didactic lectures and practical workshops related to emergency care. Students are introduced to common clinical scenarios encountered in local ED practice and allowed to conduct supervised clinical activities. Graduates of the medical school have to pass basic and advanced life support courses (BLS \& ACLS) as part of their internship requirements in order to qualify for medical practice.

EM in postgraduate medical education

Sultan Qaboos University was established in 1986. The first batch of medical students had graduated in 1993. With this graduation, the need for a national residency training program was realized as the next essential step. The Oman Medical Specialty Board (OMSB) was established in 1997 as the supervising and organizing body for all postgraduate training programs in the country. The recognition of the OMSB as an official authority was further enhanced by reestablishing it according to a Royal Decree in 2006. This was a landmark in the official recognition of local specialty training programs. Currently, the OMSB runs 15 programs for residency training.

EM postgraduate residency training was established in 1999, which makes it one of the earliest EM programs in the region. The initial program was a 6-year residency, half of which was spent in recognized EDs with the other half comprising rotations in various clinical departments of various durations. Recently, the program was restructured to a 5-year residency. Research has become a mandatory requirement, with specific time periods provisioned for the same within the new program. Currently, many of the early graduates of the program hold key positions in EDs in tertiary and certain secondary hospitals. In addition to the local residency program, some physicians get the opportunity for overseas residency, which provides another source for qualified EM physicians and enriches the local setting with diverse professional backgrounds. Several candidates have the opportunity as well for subspecialization in EM through government-sponsored overseas scholarships.

\section{Emergency nursing}

Emergency nursing is an essential component of any modern emergency service. With the development of the health care system in Oman in general, and the evolving specialty of EM in particular, there has been a parallel recognition of the need to develop specialized emergency nurses who can successfully support the system via their proficient knowledge and competent skills in emergency care. A 4-month on the job emergency nursing training program was started by the $\mathrm{MoH} \sim 10$ years ago. Recently, a 1-year "adult critical care" nursing post-basic program incorporated emergency nursing in addition to its intensive care nursing curriculum. Many of the nurses currently working in EDs are graduates of either of these two programs. 


\section{Continuing education in emergency care}

Most of the secondary and tertiary hospitals in Oman have BLS \& ACLS courses available locally. Khoula Hospital, as the premier trauma center in the country, has developed an "early management of polytrauma" course that targets primary and emergency care workers. The OMSB has recently announced a project to establish the first medical simulation center in Oman with an aim to combine training techniques from high-risk professions in EM, critical care, and surgical specialties with the latest medical simulation technologies. The proposed simulation center will incorporate 15 courses, mainly comprising those in emergency care. Recently, an American Heart Association (AHA)affiliated private educational medical center has been launched, which provides primarily emergency care training for health care professionals, as well as first aid training for the public. This may prove useful in providing quality emergency training among concerned professionals.

\section{Academic EM}

Despite the various developments in EM as a specialty in Oman, it still largely lacks an academic flavor. There is as yet no organizing society that gathers all emergency care professionals in the country under its umbrella. Considering the ample opportunities for research activities in the field, there is a need for an active research movement that addresses the local portfolio of emergency care. Including research as an essential component of the current residency program is an important and vital step forward to this end. Two international EM conferences have been held in the country so far in 2007 and 2009.

\section{Future challenges}

Oman has taken a remarkable leap in developing EM as a specialty over the last decade. Establishing EM as a specialty — academically and in practice-was an important step in the development of emergency care in Oman. Nevertheless, it is still early to term the existing emergency system as being mature. If we adopt the Arnold classification [5], then we may consider Oman's emergency care system as "developing." As with any developing system, the challenges faced remain a source of opportunity as well as threats, depending upon the approach adopted in tackling them. Several aspects need to be addressed in future plans, including clinical, academic, and economic challenges as well as social changes that may impact the practice and shape its future.

Clinical challenges include the provision of adequately trained ED staff with appropriate equipment for best practices. Prehospital emergency care would face the challenge of extending its umbrella of operations throughout the country. Provision of primary emergency care will be an important step if emergency care is to maintain the chain of survival. This would not be possible through EDs restricted to secondary and tertiary hospitals only. Primary health care centers play a vital role in the chain and should, therefore, be adequately equipped with staff trained and prepared for such a role. Threats of natural or man-made disasters in Oman are not negligible. Emergency care practitioners should be prepared to handle major disasters if they do take place. Prehospital, primary, and hospitalbased workers shall form a continuous chain of emergency care.

Academic EM needs a boost in order to establish its presence. Emergency care providers should work to form an organizing body that helps in structuring and organizing emergency practice. The proposed society shall also join the efforts of different disciplines involved in emergency care, whether medical or nonmedical. Research should be encouraged, not only in large EDs with academic interests but also in prehospital and primary care settings. Academic EDs have a considerable responsibility in establishing emergency care-related activities outside its walls. Emergency care education should also involve the public in order to complete the chain of survival. Academic EM has the great responsibility of translating societal needs into proper EM practices and not merely applying imported practices to local settings.

Social changes in the community are inseparable from the above challenges. It should be remembered that EM is a product of its cultural context and that social and economic backgrounds largely influence the way it is practiced and developed. The rapid socioeconomic transition of the country over the past 3 decades has been associated with an epidemiologic transition of disease patterns with reduction in communicable diseases in favor of alarmingly growing rates of lifestyle-related diseases of affluence, such as diabetes, hypertension, and ischemic heart disease in the country [6-8]. The youth is increasingly prone to modern plagues such as substance abuse and dependency, with all its acute and chronic risks [9, 10]. Further, with rapid industrial growth and urbanization, injuries in the workforce are likely to increase significantly. Road traffic accidents (RTA) continue to be a major concern for the country [11]. RTA mortality and morbidity tolls yearly number in the thousands, mainly among the younger generation. Delivering trauma care with acceptable standards all over the country continues to be a core issue for policymakers.

EM in Oman has recently advanced at significant speed with impressive results comparable to the efficiency of the health care system in the country. Although heading toward 
maturity, the system should take into consideration all future challenges. Having said so, these challenges could themselves prove to be an opportunity for the system to establish its presence as a practice that stems from societal needs and addresses them effectively and efficiently in a timely manner.

\section{Conflict of interest None.}

\section{References}

1. Jessop E (1979) Desert medicine in Oman. BMJ 2:1352-1353

2. 2003 census: population indicators. Sultanate of Oman: Ministry of National Economy. Available via: http://www.omancensus.net/ english/population_indicators.asp\#1. Accessed 24 Jul 2009

3. World Health Organization (2000) The World Health Report 2000 health systems: improving performance

4. Al-Shaqsi SZ (2009) EMS in the Sultanate of Oman. Resuscitation 80:740-742

5. Arnold JL (1999) International emergency medicine and the recent development of emergency medicine worldwide. Ann Emerg Med 33(1):97-103

6. Al-Adawi S (2006) Emergence of diseases of affluence in Oman: where do they feature in the health research agenda? SQU J Sci Res Med Sci 6(2):3-9

7. Al-Lawati J, Mabry R, Mohammed AJ (2008) Addressing the threat of chronic diseases in Oman. Preventing chronic disease; 5 (3). Available via: http://www.cdc.gov/PCD/issues/2008/jul/ 07_0086.htm. Accessed 7 Jul 2008

8. Ganguly SS, Al-Shafaee MA, Al-Lawati JA, Dutta PK, Duttagupta KK (2009) Epidemiological transition of some diseases in Oman: a situational analysis. East Mediterr Health J 15(1):209-218
9. Al-Harthi A, Al-Adawi S (2002) Enemy within? The silent epidemic of substance dependency in GCC countries. SQU J Sci Res Med Sci 4(1):1

10. AlMarri TSK, Oei TPS (2009) Alcohol and substance use in the Arabian Gulf region: a review. Int J Psychol 44(3):222-233

11. Al-Kharusi W (2008) Update on road traffic crashes: progress in the Middle East. Clin Orthop Relat Res 466:2457-2464

Nasser Al-Azri is a qualified emergency physician working currently for the Petroleum Development Oman Company, Medical Department. In addition to his skills in emergency medicine he also has an academic interest in teaching emergency and life support skills for medical professionals and the public. His current work provided him the opportunity to combine his emergency skills and experience along with occupational health needs. He completed his BSc in Health Sciences from Sultan Qaboos University College of Medicine in 1996 and received an MD with distinction in Family \& Community Health (FAMCO). Subsequently, he acquired MRCS (A\&E) from the Royal College of Surgeons, Edinburgh, UK. He is currently in charge of the medical emergency response system in the largest oil corporate in Oman. He works on developing medical emergency and disaster management plans in addition to his prehospital and clinical activities. $\mathrm{He}$ has extensive academic involvement in several health care institutions. He has initiated and coordinated an advanced cardiac life support (ACLS) course at Ibri Regional Hospital since 2000. He has also been teaching the same course at Sultan Qaboos University Hospital and Khoula Hospital, as well as basic life support. He is also an instructor for the early management of polytrauma (EMPT) course at Khoula Hospital. In addition, he has been involved in teaching first aid and CPR for the public. In line with his academic interest, he has attended several conferences and presented several papers mainly on aspects of emergency medicine practice and medical education. He has been an invited speaker on topics in emergency medicine at local and regional conferences. 